\title{
BMJ Open Prescribing of antipsychotics in UK primary care: a cohort study
}

\author{
Louise Marston, ${ }^{1}$ Irwin Nazareth, ${ }^{1}$ Irene Petersen, ${ }^{1}$ Kate Walters, ${ }^{1}$ \\ David P J Osborn ${ }^{2,3}$
}

To cite: Marston L,

Nazareth I, Petersen I, et al. Prescribing of antipsychotics in UK primary care: a cohort study. BMJ Open 2014;4: e006135. doi:10.1136/ bmjopen-2014-006135

\section{- Prepublication history and} additional material is available. To view please visit the journal (http://dx.doi.org/ 10.1136/bmjopen-2014006135).

Received 16 July 2014 Revised 15 October 2014 Accepted 17 November 2014

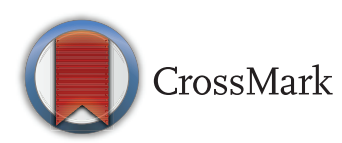

\footnotetext{
${ }^{1}$ Research Department of Primary Care and Population Health, University College London, London, UK

${ }^{2}$ Division of Psychiatry, University College London, London, UK

${ }^{3}$ Camden and Islington NHS Foundation Trust, London, UK
}

Correspondence to Dr Louise Marston; I.marston@ucl.ac.uk

\section{ABSTRACT}

Objective: To examine the recorded indication for antipsychotic prescriptions in UK primary care.

Design: Cohort study.

Setting: Primary care.

Participants: Individuals prescribed antipsychotics between 2007 and 2011.

Measures: The proportion of individuals prescribed antipsychotics with a diagnosis of (1) psychosis and bipolar disorder, (2) other diagnoses including depression, anxiety and dementia and (3) none of these diagnoses.

Results: We identified 47724 individuals prescribed antipsychotic agents. 13941 received first-generation agents and 27966 received second-generation agents. The rates of prescribing were higher in females (incidence rate ratio (IRR) 1.092 ( $95 \% \mathrm{Cl} 1.088$ to 1.095), older people (80+ vs 40-49; IRR 2.234 (2.222 to 2.246)) and in those from the most deprived areas (most deprived vs least deprived IRR 3.487 (3.567 to 3.606 ). Of those receiving first-generation antipsychotics, less than $50 \%$ had a diagnosis of psychosis/bipolar disorder. For the secondgeneration agents, the numbers ranged from 4824 (36\%) for quetiapine to $7094(62 \%)$ for olanzapine. In patients without psychosis/bipolar disorder, common diagnoses included anxiety, depression, dementia, sleep and personality disorders. For example, in risperidone users, $14 \%$ had an anxiety code, $22 \%$ depression, $12 \%$ dementia, $11 \%$ sleep disorder and $4 \%$ personality disorder. The median daily doses and duration of treatment were greater in those with schizophrenia (eg, risperidone median daily dose $4 \mathrm{mg}$; IQR 2-6: median duration 1.2 years) than in those with non-psychotic/bipolar disorders such as depression or anxiety (eg, risperidone $1 \mathrm{mg}$; IQR 1-2: 0.6 years). A relatively large proportion (between $6 \%$ and $17 \%$ ) of people receiving individual antipsychotics had none of the diagnoses stated above. Conclusions: In UK primary care, a large proportion of people prescribed antipsychotics have no record of psychotic or bipolar disorder. They are often older people with conditions including dementia, non-psychotic depression, anxiety and sleep disorders.

\section{BACKGROUND}

Antipsychotic medications are the first-line pharmacological intervention for severe mental illnesses (SMI) such as schizophrenia and other psychoses. However, they are also

\section{Strengths and limitations of this study}

We determined the likely indication for antipsychotic prescriptions in a large, representative sample of people in UK primary care. The data source contained accurate prescribing information, although prescriptions issued in secondary care would not have been captured. Diagnoses of severe mental illnesses have been validated in primary care. The nature of the data did not allow us to determine the clinicians' rationale for prescribing antipsychotics to people without psychoses or bipolar disorder diagnoses.

- Less than half of the people prescribed the most common first-generation antipsychotics in UK primary care have a diagnosis of psychosis or bipolar disorder.

- Findings were similar for second-generation agents, although $62 \%$ of people receiving olanzapine did have a diagnosis of psychosis or bipolar disorder.

- These agents are more commonly prescribed to older people, despite the propensity of this age group to develop side effects.

- Antipsychotics are still commonly prescribed to people with a diagnosis of dementia, contrary to clinical guidance, and this needs further attention in UK primary care.

- Other common diagnoses included depression, anxiety disorders, personality disorders and attention deficit hyperactivity disorder (ADHD), while up to $17 \%$ of people receiving antipsychotics had none of the diagnoses we explored.

increasingly prescribed for the treatment of bipolar affective disorder. They are not routinely recommended for other mental health conditions such as depression, sleep disorders or obsessive compulsive disorder (OCD). There is concern about rates of antipsychotic prescribing in dementia since they may be associated with increased rates of strokes and all-cause mortality. ${ }^{12}$ Prescription of antipsychotics requires caution given their association with a range of serious adverse effects including extra-pyramidal side effects with first-generation agents, weight gain and lipid/ glucose dysregulation with second-generation 
agents. International guidelines stress the importance of regular monitoring of body mass index (BMI), glucose and lipids in people receiving repeat prescriptions of these agents, given their propensity to affect these parameters.

National guidelines do recommend antipsychotics for the relatively rare condition of psychotic depression and as a possible intervention for treatment-resistant cases of severe depression ${ }^{3}$ and $\mathrm{OCD}^{4}$. In clinical practice, these agents may be prescribed 'off-label' for patients who do not have a diagnosis of SMI in their clinical notes. They are sometimes used to augment antidepressants in complex or treatment-resistant cases of OCD, anxiety and personality disorders. Although antipsychotics may be used in sleep disorders, treatment guidelines do not recommend using such agents on account of their side effect profiles. ${ }^{5}$ Guidelines for borderline personality disorder recommend that short-term treatment with antipsychotics (up to a week) may be beneficial in crisis situations or when comorbid psychotic symptoms occur. ${ }^{6}$

Our aim was to examine the recorded indication for antipsychotic prescriptions in UK primary care. Further, we sought to describe the prescribing pattern by diagnostic group.

\section{Objectives}

1. To examine the likely indications for antipsychotic prescribing in UK primary care.

2. To describe the prescribing patterns (duration of treatment and average dose) in three broad groups of people who may receive antipsychotics in primary care:

A. Those with a diagnosis of SMI (psychosis or bipolar disorder);

B. Those without a diagnosis of SMI, but with a mental health diagnosis such as depression, personality disorder or dementia;

C. Individuals with none of these conditions in their general practice notes.

\section{METHOD}

Study design

Cohort study.

\section{Setting}

Primary care in the UK.

\section{Data source}

We used data from The Health Improvement Network $(\mathrm{THIN}),{ }^{7}$ a UK primary care database like Clinical Practice Research Datalink (CPRD) ${ }^{8}$ which is based on data from routine clinical care and administration. THIN data, like those from the CPRD, are derived from practices using Vision software and are available anonymously for research. ${ }^{9}$ The database includes demographics and the Townsend deprivation quintile. The latter is a validated measure of social deprivation, attributed to the patient's geographical postcode, covering a small area of approximately 150 households. ${ }^{10}$ Data such as diagnoses and symptoms are entered as Read codes, a hierarchical classification system. ${ }^{11}$ The database also includes records of all prescriptions issued and these are linked to the British National Formulary (BNF).$^{12}$ The exception to this is clozapine, which is almost exclusively prescribed and monitored in hospital outpatient clinics. Prescribing is well recorded in THIN because all prescriptions from general practice are generated via the computerised system. This information produces a longitudinal record for each individual in the database. Ninety-eight per cent of the UK population is registered with a general practice $^{9}$; THIN is representative of the UK population in general in terms of their demographic characteristics ${ }^{13}$ and practices are geographically spread across the UK. At the time of this study, the full database included almost 10 million patients. For quality purposes, data were extracted only after the date when there was evidence that general practices were using their computer system fully (acceptable computer use (ACU) dates ${ }^{14}$ ) and mortality were adequately recorded (acceptable mortality rate $(\mathrm{AMR})^{15}$ ).

\section{Participants}

We initially included all people who had received at least one prescription for any antipsychotic medication after 1 January 2007 or after the date at which practice met quality standards. The follow-up ended at the earliest of date of (1) death, (2) transferring out of the practice, (3) last data collection from the practice, (4) reaching the age of 100 years or (5) 31 December 2011. The start of follow-up for each individual was the date of the first antipsychotic prescription during these periods. We excluded individuals with less than 6 months of follow-up data.

\section{Antipsychotic data}

First, we determined the overall rates of prescribing of all first-generation and second-generation antipsychotics in UK primary care (see online supplementary appendix 2 for the full list of first-generation and secondgeneration antipsychotics). Subsequently, we focused on the three most commonly prescribed first-generation (haloperidol, chlorpromazine and trifluoperazine) and second-generation agents (olanzapine, quetiapine and risperidone). We determined the average daily dose prescribed for each antipsychotic during the follow-up period, as well as the length of time for which antipsychotics had been prescribed. We did this by using data on the strength of the antipsychotics prescribed, the total amount prescribed and the dose per day. From this information, it was possible to calculate the total possible milligram per prescription. These were cumulated for all prescriptions of a given antipsychotic. The period of time on a given antipsychotic was calculated using the first and last prescription dates, adding the number of days the final prescription was expected to last, if it were to be taken as directed. We excluded the total daily doses, which were implausibly high for community 
prescribing of antipsychotics, since these were likely to represent erroneous entries. We defined the upper threshold at twice the maximum recommended daily dose in the $\mathrm{BNF}^{12}$ namely over $60 \mathrm{mg}$ for haloperidol, over $2000 \mathrm{mg}$ for chlorpromazine, over $120 \mathrm{mg}$ for trifluoperazine, over $40 \mathrm{mg}$ for olanzapine, over $1500 \mathrm{mg}$ for quetiapine and over $32 \mathrm{mg}$ for risperidone. Relatively few (221) prescriptions were excluded for this reason.

\section{Mental health conditions}

We defined severe mental illness as schizophrenia-like disorders, bipolar-affective disorders and other nonorganic psychoses such as delusional disorder, 'psychoses not otherwise specified' and severe depression with psychoses (see online supplementary appendix 1). Read codes for SMI diagnoses have been previously been validated. ${ }^{16}$ We identified an additional category for people who were included on the practice's SMI register without having a Read code for the SMI diagnoses above (a general practitioner (GP) SMI register is required as part of the GP contract in the UK since 2004). Hardoon et $a l^{17}$ determined that the prevalence of SMI in THIN is similar to that of epidemiological studies.

Next, we identified common mental health conditions for which antipsychotics might be prescribed off-label, using diagnostic Read code lists, compiled by two clinical academics, a GP and a psychiatrist. ${ }^{18}$ These non-SMI conditions comprised depression, anxiety disorders, sleep disorders (insomnia, non-specific sleep disorders, apnoea, hypersomnia), dementia, attention deficit and hyperactivity disorder, personality disorders, post-traumatic stress disorder and OCD. These have not been validated; however, we have reported on trends in anxiety and depression symptoms and diagnoses as recorded in THIN. ${ }^{192}$

We created a diagnostic hierarchy for people with more than one mental health diagnosis in their clinical notes. Hence, if a patient ever had an SMI diagnosis, we considered this as an indication for antipsychotics. However, if there was no SMI diagnosis, then all non-SMI diagnoses were extracted and included in this study. In other words, the non-SMI diagnoses were not mutually exclusive; hence, a person could be counted both as a case of anxiety and as a case of OCD.

\section{Statistical analysis}

We calculated the rates of prescribing any antipsychotics, per 100000 person years at risk (PYAR). We then calculated the rates of any first-generation or secondgeneration antipsychotics, after which we determined the rates of prescribing individual agents for the three most commonly prescribed first-generation and secondgeneration antipsychotic agents. Multivariable Poisson regression was used to determine associations between sex, age group, Townsend deprivation quintile, calendar year and (1) overall antipsychotic prescribing, (2) all first-generation and second-generation antipsychotic agents and (3) the six most commonly prescribed individual antipsychotics. For these analyses, we defined the population at risk as the total population registered with the general practices in the period 2007-2011.

We calculated the frequencies (\%) for each indication (diagnosis) and for each of the six most commonly prescribed antipsychotics. We also calculated the median (IQR) daily dose in milligrams and the length of time prescribed for a given antipsychotic within three groups: the SMI (psychosis/bipolar) subgroup, the group with non-SMI diagnoses and the group with no record of these diagnoses.

All analyses were carried out using Stata V.13. ${ }^{21}$

\section{RESULTS}

We identified 47724 eligible individuals who were prescribed antipsychotic medications. Of these, 13941 were solely prescribed first-generation antipsychotics; 27966 were prescribed second-generation antipsychotics; and 5817 received both classes of agents during their follow-up period (figure 1). The median length of follow-up for people receiving any antipsychotic was 2.4 years (IQR 1.3-4.1). The length of the follow-up was slightly longer for those receiving both first-generation and secondgeneration antipsychotics (3 years; IQR 1.7-4.7).

\section{Rates of antipsychotic prescribing by sociodemographic characteristics and over time}

Overall, $1 \%$ of individuals received an antipsychotic at some time over the study period. For women, the rate of prescribing any antipsychotic was 699/100 000 PYAR (95\% CI 693 to 705 ) as compared to $612 / 100000$ PYAR (95\% CI 607 to 617 ) for men. Individuals aged above 80 years were more likely to receive antipsychotics (Incidence rate ratio (IRR) 2.234; 95\% CI 2.222 to 2.246 as compared with those aged 40-49 years). In contrast, those under the age of 18 and those aged between 18 and 29 were much less likely to receive antipsychotics (table 1). Those living in the most deprived areas were more than three times as likely to receive antipsychotics as those in the least-deprived areas (IRR 3.587 (95\% CI 3.567 to 3.606 ; table 1 ). These patterns were also observed when the subgroups that had been prescribed first-generation and second-generation antipsychotics were examined separately (table 1 ).

The three most commonly prescribed first-generation antipsychotics were haloperidol, chlorpromazine and trifluoperazine, while olanzapine, risperidone and quetiapine were the most commonly issued second-generation agents (tables 2 and 3). The rates of prescribing these individual agents followed patterns similar to the aggregate results in terms of their distributions by age and deprivation. Haloperidol and trifluoperazine were more commonly prescribed to women, as was quetiapine, while the rates of prescribing risperidone and olanzapine were lower in women. Few under-18s received antipsychotics, but compared to other agents, risperidone was prescribed far more commonly to this young age group (table 3). Over the five years of the study (2007- 
Figure 1 Flow of individuals through the study. FGA, first generation antipsychotics; SGA, second generation antipsychotics.

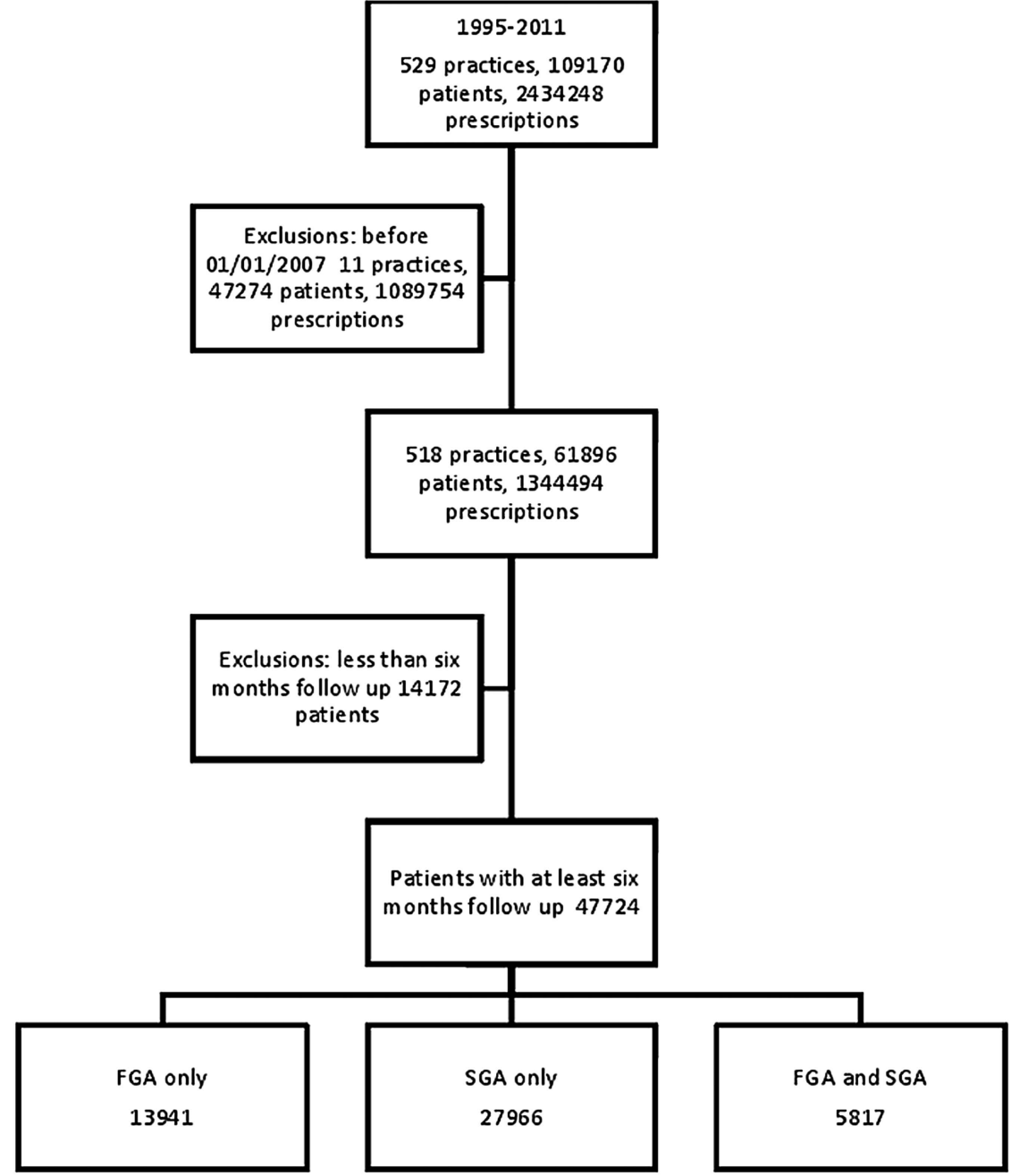

2011), the rates of prescribing for each first-generation agent decreased, while quetiapine prescription rates increased the most over time. For example, IRR for trifluoperazine in 2011 (reference category is 2007) was 0.665 (95\% CI 0.645 to 0.685 ) and IRR for quetiapine in 2011 (reference category is 2007) was 1.480 (95\% CI 1.463 to 1.497$)$. There was a smaller increase in the rates of prescriptions for risperidone and olanzapine (table 3).

\section{Records of mental health conditions in people prescribed antipsychotics}

For people prescribed the three most common firstgeneration antipsychotics, the proportion with a Read code for SMI (psychotic or bipolar disorder) varied between $27 \% \quad(n=1331)$ for haloperidol and $35 \%$ $(n=1545)$ for chlorpromazine (table 4). The most common diagnosis was schizophrenia and related conditions. For second-generation antipsychotics, only $36 \%$ $(n=4824)$ of those prescribed quetiapine had an SMI record, compared to $46 \%(n=4597)$ of those receiving risperidone and $62 \%(\mathrm{n}=7094)$ of those receiving olanzapine (table 4). More than half of the people receiving first-generation antipsychotics had no SMI diagnosis recorded in their notes, but they did have a code for one of the non-SMI mental health conditions. The most common conditions were anxiety, depression and sleep disorders. Almost one-third of the people receiving haloperidol had a record of dementia. For second-generation agents, the proportions with non-SMI diagnoses were similar, although the number of people with a record of dementia was highest for quetiapine (26\% of prescriptions). Between $12 \%$ and $17 \%$ of the people who had been prescribed first-generation agents had no record of an SMI or of any non-SMI mental health diagnosis.

The median daily dose for antipsychotics was higher in those who did have an SMI diagnosis, and was highest among those with records of schizophrenia (table 5). Within the non-SMI groups, the median daily doses were similar, although the highest doses were observed in people with a record of a sleep disorder or a personality disorder. The longest durations of antipsychotic treatment were generally observed in people with a diagnosis of schizophrenia or in those who were included on the SMI register in general practice (see online supplementary table S1). Within the non-SMI group, the duration of treatment showed little variation between diagnoses, although the median length of treatment seemed longest in people with dementia or attention deficit hyperactivity disorder (ADHD). 
Table 1 Rates of antipsychotic prescribing by class of antipsychotic, age gender and social deprivation

\begin{tabular}{|c|c|c|c|c|c|c|c|c|c|c|c|c|c|c|c|c|}
\hline & \multicolumn{4}{|c|}{ Any antipsychotic } & \multicolumn{4}{|c|}{ Any first-generation antipsychotic } & \multicolumn{4}{|c|}{ Any second-generation antipsychotic } & \multicolumn{4}{|c|}{$\begin{array}{l}\text { First-generation and second-generation } \\
\text { antipsychotics }\end{array}$} \\
\hline & Rate per & & & & Rate per & & & & Rate per & & & & Rate per & & & \\
\hline & 100000 PYAR & $95 \% \mathrm{Cl}$ & IRR $^{*}$ & $95 \% \mathrm{Cl}$ & 100000 PYAR & $95 \% \mathrm{Cl}$ & $\mathbf{I R R}^{\star}$ & $95 \% \mathrm{Cl}$ & 100000 PYAR & $95 \% \mathrm{Cl}$ & $\mathbf{I R R}^{\star}$ & $95 \% \mathrm{Cl}$ & 100000 PYAR & $95 \% \mathrm{Cl}$ & IRR $^{*}$ & $95 \% \mathrm{Cl}$ \\
\hline Male & 612 & (607 to 617 ) & 1.000 & & 197 & (194 to 200) & 1.000 & & 458 & (454 to 462 ) & 1.000 & & 43 & (41 to 44 ) & 1.000 & \\
\hline Female & 699 & (693 to 705 ) & 1.092 & (1.088 to 1.095$)$ & 256 & (253 to 259 ) & 1.204 & (1.196 to 1.211$)$ & 489 & (484 to 493 ) & 1.050 & (1.046 to 1.054$)$ & 46 & (44 to 47 ) & 1.010 & (1.096 to 1.103 \\
\hline Under 18 & 63 & (61 to 66$)$ & 0.044 & ( 0.044 to 0.045$)$ & 5 & (4 to 5 ) & 0.009 & ( 0.008 to 0.009$)$ & 59 & (57 to 62 ) & 0.058 & ( 0.057 to 0.059$)$ & 0.6 & (0.4 to 0.9$)$ & 0.026 & ( 0.026 to 0.027 \\
\hline $18-29$ & 459 & (451 to 467 ) & 0.351 & ( 0.349 to 0.353 ) & 111 & (107 to 115 ) & 0.223 & ( 0.220 to 0.227$)$ & 376 & (369 to 383 ) & 0.401 & (0.398 to 0.404$)$ & 28 & (26 to 30$)$ & 0.348 & ( 0.346 to 0.351 \\
\hline 30-39 & 817 & (806 to 828 ) & 0.804 & (0.799 to 0.808$)$ & 238 & (232 to 244 ) & 0.643 & ( 0.636 to 0.650 ) & 638 & (628 to 648 ) & 0.867 & ( 0.861 to 0.872 ) & 58 & (56 to 62 ) & 0.803 & ( 0.799 to 0.807 \\
\hline $40-49$ & 852 & (842 to 863 ) & 1.000 & & 289 & (283 to 295 ) & 1.000 & & 628 & (619 to 637 ) & 1.000 & & 64 & (62 to 67 ) & 1.000 & \\
\hline 50-59 & 712 & (701 to 723 ) & 0.872 & ( 0.867 to 0.877 ) & 283 & (276 to 290 ) & 1.045 & (1.035 to 1.056$)$ & 483 & (474 to 492 ) & 0.804 & (0.799 to 0.809 ) & 54 & (51 to 57 ) & 0.872 & ( 0.867 to 0.877 \\
\hline $60-69$ & 642 & (631 to 653 ) & 0.824 & ( 0.819 to 0.829 ) & 281 & (274 to 289 ) & 1.039 & (1.029 to 1.050$)$ & 406 & (398 to 415 ) & 0.740 & ( 0.735 to 0.745 ) & 46 & (43 to 49 ) & 0.824 & ( 0.819 to 0.829 \\
\hline 70-79 & 842 & (827 to 857 ) & 0.973 & ( 0.967 to 0.980 ) & 350 & (341 to 360 ) & 1.192 & (1.179 to 1.205 ) & 546 & (534 to 559 ) & 0.888 & ( 0.881 to 0.894 ) & 54 & (51 to 58 ) & 0.971 & ( 0.965 to 0.977 \\
\hline $\begin{array}{l}80+ \\
\text { Townsend }\end{array}$ & 2201 & (2170 to 2231) & 2.234 & (2.222 to 2.246 ) & 793 & (775 to 811 ) & 2.358 & (2.334 to 2.382 ) & 1529 & (1504 to 1555 ) & 2.185 & (2.171 to 2.199 ) & 121 & (114 to 129 ) & 2.221 & (2.209 to 2.234 \\
\hline Least deprived & 403 & (398 to 409 ) & 1.000 & & 138 & (135 to 142 ) & 1.000 & & 291 & (286 to 296 ) & 1.000 & & 26 & (24 to 27) & 1.000 & \\
\hline 2 & 499 & (492 to 506 ) & 1.211 & (1.203 to 1.218$)$ & 180 & (176 to 184 ) & 1.251 & (1.237 to 1.265$)$ & 351 & (345 to 357 ) & 1.194 & (1.186 to 1.203 ) & 33 & (31 to 35 ) & 1.214 & (1.207 to 1.222 \\
\hline 3 & 645 & (637 to 653 ) & 1.707 & (1.697 to 1.716$)$ & 223 & (218 to 228) & 1.764 & (1.745 to 1.782 ) & 465 & (458 to 472 ) & 1.683 & (1.672 to 1.695 ) & 43 & (41 to 45 ) & 1.714 & (1.705 to 1.724 \\
\hline 4 & 844 & (834 to 854 ) & 2.457 & (2.443 to 2.470 ) & 295 & (290 to 301 ) & 2.516 & (2.491 to 2.542 ) & 608 & (600 to 616 ) & 2.432 & (2.416 to 2.448 ) & 59 & (57 to 62 ) & 2.476 & (2.463 to 2.489 \\
\hline Most deprived & 1158 & (1145 to 1172 ) & 3.587 & (3.567 to 3.606 ) & 386 & (378 to 394 ) & 3.649 & (3.612 to 3.686 ) & 853 & ( 841 to 865 ) & 3.560 & (3.537 to 3.583 ) & 80 & (76 to 84 ) & 3.613 & (3.593 to 3.633 \\
\hline $\begin{array}{l}\text { Missing } \\
\text { Year }\end{array}$ & 806 & (781 to 830 ) & 2.282 & (2.259 to 2.305 ) & 270 & (256 to 284 ) & 2.360 & (2.315 to 2.406 ) & 586 & (566 to 608 ) & 2.250 & (2.223 to 2.277 ) & 51 & (45 to 57 ) & 2.187 & (2.165 to 2.210 \\
\hline 2007 & 591 & (584 to 599 ) & 1.000 & & 236 & (231 to 241 ) & 1.000 & & 399 & (393 to 405 ) & 1.000 & & 44 & (42 to 46 ) & 1.000 & \\
\hline 2008 & 654 & (646 to 663 ) & 1.075 & (1.069 to 1.080 ) & 243 & (238 to 248 ) & 0.990 & ( 0.981 to 1.000 ) & 456 & (449 to 463 ) & 1.118 & (1.111 to 1.125 ) & 45 & (43 to 47 ) & 1.075 & (1.070 to 1.081 \\
\hline 2009 & 679 & (670 to 687 ) & 1.110 & (1.104 to 1.115 ) & 237 & (232 to 242 ) & 0.946 & ( 0.938 to 0.955$)$ & 487 & (480 to 494 ) & 1.194 & (1.186 to 1.201 ) & 45 & (43 to 47 ) & 1.108 & (1.102 to 1.114 \\
\hline 2010 & 718 & (710 to 727 ) & 1.151 & (1.145 to 1.157$)$ & 227 & (222 to 232) & 0.880 & (0.872 to 0.888 ) & 536 & (529 to 543 ) & 1.290 & (1.282 to 1.298 ) & 44 & (42 to 47 ) & 1.147 & (1.141 to 1.153 \\
\hline 2011 & 637 & (629 to 646 ) & 1.065 & (1.059 to 1.071$)$ & 189 & (184 to 193 ) & 0.745 & ( 0.737 to 0.752$)$ & 492 & (484 to 499 ) & 1.230 & (1.222 to 1.238 ) & 43 & (41 to 45 ) & 1.055 & (1.050 to 1.061 \\
\hline
\end{tabular}




\begin{tabular}{|c|c|c|c|c|c|c|c|c|c|c|c|c|}
\hline & Haloperid & & & & Chlorpror & nazine & & & Trifluoper & azine & & \\
\hline Characteristic & $\begin{array}{l}\text { Rate per } \\
100000 \\
\text { PYAR }\end{array}$ & $95 \% \mathrm{Cl}$ & IRR* $^{*}$ & $95 \% \mathrm{Cl}$ & $\begin{array}{l}\text { Rate per } \\
100000 \\
\text { PYAR }\end{array}$ & $95 \% \mathrm{Cl}$ & IRR* $^{*}$ & $95 \% \mathrm{Cl}$ & $\begin{array}{l}\text { Rate per } \\
100000 \\
\text { PYAR }\end{array}$ & $95 \% \mathrm{Cl}$ & IRR* $^{*}$ & $95 \% \mathrm{Cl}$ \\
\hline Male & 42 & (41 to 44$)$ & 1.000 & & 51 & (50 to 53 ) & 1.000 & & 22 & (21 to 23 ) & 1.000 & \\
\hline Female & 55 & (54 to 57 ) & 1.123 & (1.107 to 1.138$)$ & 52 & (50 to 53$)$ & 1.121 & (1.107 to 1.135$)$ & 36 & (35 to 38 ) & 1.577 & (1.547 to 1.607$)$ \\
\hline Under 18 & 1 & (1 to 2 ) & 0.017 & (0.015 to 0.019$)$ & 0.6 & (0.4 to 0.9$)$ & 0.004 & (0.003 to 0.004$)$ & 0.6 & (0.4 to 0.9$)$ & 0.006 & (0.005 to 0.008$)$ \\
\hline 18-29 & 16 & (15 to 18 ) & 0.204 & (0.196 to 0.213$)$ & 33 & (31 to 35 ) & 0.231 & (0.225 to 0.237$)$ & 13 & (12 to 15$)$ & 0.195 & (0.186 to 0.205$)$ \\
\hline 30-39 & 35 & (33 to 38 ) & 0.659 & (0.641 to 0.678$)$ & 72 & (68 to 75$)$ & 0.640 & (0.628 to 0.653 ) & 30 & (28 to 32 ) & 0.634 & (0.613 to 0.655$)$ \\
\hline 40-49 & 42 & (40 to 44 ) & 1.000 & & 85 & (82 to 89 ) & 1.000 & & 37 & (35 to 40 ) & 1.000 & \\
\hline 50-59 & 44 & (42 to 47 ) & 1.085 & (1.058 to 1.112 ) & 77 & (74 to 81 ) & 0.992 & (0.974 to 1.010$)$ & 38 & (35 to 40 ) & 1.046 & (1.015 to 1.078$)$ \\
\hline 60-69 & 51 & (48 to 54 ) & 1.175 & (1.145 to 1.205$)$ & 63 & (60 to 67$)$ & 0.822 & (0.806 to 0.839$)$ & 46 & (43 to 49 ) & 1.378 & (1.339 to 1.419$)$ \\
\hline 70-79 & 98 & (93 to 104 ) & 2.123 & (2.073 to 2.175$)$ & 54 & (50 to 58 ) & 0.613 & (0.598 to 0.629$)$ & 54 & (50 to 58 ) & 1.739 & (1.687 to 1.792 ) \\
\hline $\begin{array}{l}80+ \\
\text { Townsend }\end{array}$ & 330 & (319 to 342 ) & 5.833 & (5.710 to 5.958$)$ & 58 & (53 to 63 ) & 0.595 & $(0.578$ to 0.614$)$ & 72 & (67 to 78 ) & 1.868 & (1.808 to 1.931 ) \\
\hline Least deprived & 32 & (30 to 33 ) & 1.000 & & 24 & (22 to 25$)$ & 1.000 & & 19 & (18 to 21$)$ & 1.000 & \\
\hline 2 & 48 & (46 to 50 ) & 1.499 & (1.464 to 1.534$)$ & 33 & (32 to 35 ) & 1.225 & (1.194 to 1.257 ) & 22 & (20 to 23 ) & 1.185 & (1.146 to 1.225$)$ \\
\hline 3 & 53 & (51 to 56 ) & 1.914 & (1.871 to 1.957 ) & 46 & (44 to 48 ) & 2.117 & (2.068 to 2.167 ) & 28 & (27 to 30 ) & 1.809 & (1.754 to 1.867 ) \\
\hline 4 & 60 & (58 to 63 ) & 2.360 & (2.307 to 2.413 ) & 68 & (65 to 71$)$ & 3.131 & (3.062 to 3.202 ) & 39 & (37 to 41 ) & 2.839 & (2.756 to 2.925 ) \\
\hline Most deprived & 62 & (58 to 65$)$ & 2.666 & (2.603 to 2.731 ) & 116 & (112 to 120$)$ & 5.743 & (5.619 to 5.870 ) & 50 & (47 to 53 ) & 3.703 & (3.591 to 3.818 ) \\
\hline $\begin{array}{l}\text { Missing } \\
\text { Year }\end{array}$ & 49 & (43 to 56 ) & 2.315 & (2.217 to 2.417 ) & 95 & (86 to 103 ) & 4.103 & (3.961 to 4.250 ) & 30 & (26 to 35 ) & 2.113 & (1.987 to 2.246$)$ \\
\hline 2007 & 51 & (49 to 54 ) & 1.000 & & 58 & (55 to 60 ) & 1.000 & & 33 & (31 to 35 ) & 1.000 & \\
\hline 2008 & 54 & (52 to 56$)$ & 1.019 & (0.998 to 1.039$)$ & 56 & (54 to 59 ) & 0.973 & (0.955 to 0.992$)$ & 31 & (29 to 32 ) & 0.941 & (0.916 to 0.967$)$ \\
\hline 2009 & 52 & (50 to 54$)$ & 0.955 & (0.936 to 0.974$)$ & 53 & (51 to 56$)$ & 0.899 & (0.882 to 0.916$)$ & 29 & (27 to 31 ) & 0.899 & (0.874 to 0.924$)$ \\
\hline 2010 & 48 & (46 to 50 ) & 0.822 & (0.805 to 0.840$)$ & 47 & (45 to 49 ) & 0.824 & (0.807 to 0.840$)$ & 30 & (28 to 32 ) & 0.901 & (0.876 to 0.926$)$ \\
\hline 2011 & 39 & (37 to 41 ) & 0.684 & (0.669 to 0.700$)$ & 44 & (41 to 46$)$ & 0.751 & (0.736 to 0.766$)$ & 24 & (22 to 26$)$ & 0.665 & (0.645 to 0.685$)$ \\
\hline
\end{tabular}

Table 2 Rates of antipsychotic prescribing for the three most commonly prescribed first-generation antipsychotics

RR, incident rate ratio; PYAR, person years at risk. 


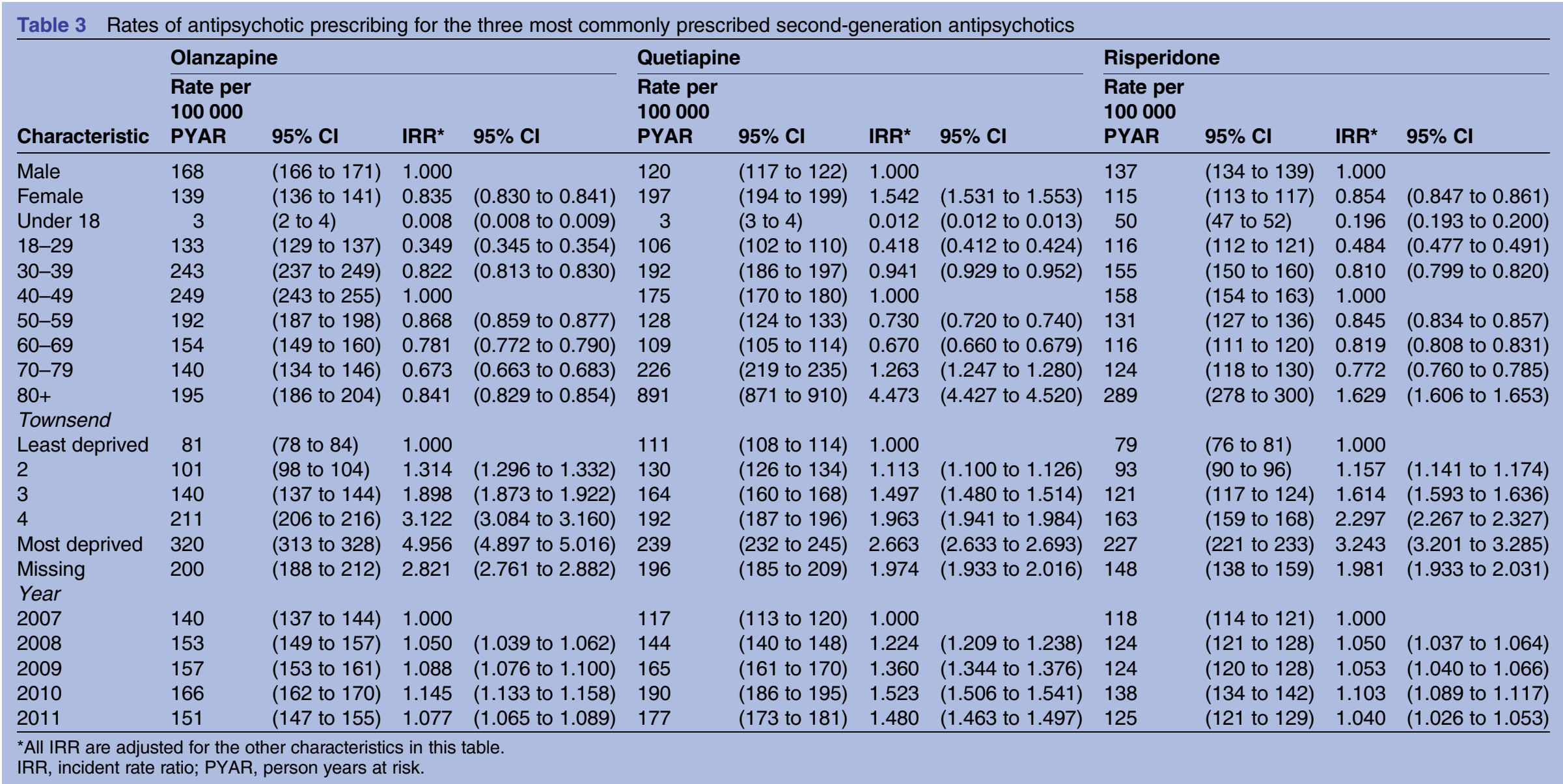

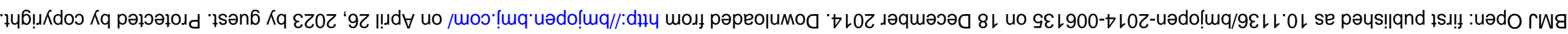


Table 4 Diagnosis by the three most commonly prescribed first-generation and second-generation antipsychotics 2007-2011

\begin{tabular}{|c|c|c|c|c|c|c|c|c|c|c|c|c|}
\hline \multirow[b]{2}{*}{ Diagnosis } & \multicolumn{2}{|c|}{$\begin{array}{l}\text { Haloperidol } \\
(\mathrm{N}=4913)\end{array}$} & \multicolumn{2}{|c|}{$\begin{array}{l}\text { Chlorpromazine } \\
(\mathrm{N}=4404)\end{array}$} & \multicolumn{2}{|c|}{$\begin{array}{l}\text { Trifluoperazine } \\
(\mathrm{N}=2633)\end{array}$} & \multicolumn{2}{|c|}{$\begin{array}{l}\text { Olanzapine } \\
(\mathrm{N}=11 \text { 502) }\end{array}$} & \multicolumn{2}{|c|}{$\begin{array}{l}\text { Quetiapine } \\
(N=13326)\end{array}$} & \multicolumn{2}{|c|}{$\begin{array}{l}\text { Risperidone } \\
(\mathrm{N}=9956)\end{array}$} \\
\hline & $\overline{\mathbf{n}}$ & Per cent & $\overline{\mathbf{n}}$ & Per cent & $\overline{\mathbf{n}}$ & Per cent & $\bar{n}$ & Per cent & $\bar{n}$ & Per cent & $\overline{\mathbf{n}}$ & Per cent \\
\hline \multicolumn{13}{|l|}{$\mathrm{SMI}^{*}$} \\
\hline Any SMI diagnosis & 1331 & 27 & 1545 & 35 & 783 & 30 & 7094 & 62 & 4824 & 36 & 4597 & 46 \\
\hline Schizophrenia & 620 & 13 & 633 & 14 & 359 & 14 & 3060 & 27 & 1489 & 11 & 2143 & 22 \\
\hline Bipolar disorder & 298 & 6 & 343 & 8 & 119 & 5 & 1655 & 14 & 1689 & 13 & 726 & 7 \\
\hline Other SMI & 267 & 5 & 334 & 8 & 203 & 8 & 1898 & 17 & 1163 & 9 & 1291 & 13 \\
\hline On SMI register only & 146 & 3 & 235 & 5 & 102 & 4 & 481 & 4 & 483 & 4 & 437 & 4 \\
\hline \multicolumn{13}{|l|}{ Non-SMI* } \\
\hline Any non-SMI diagnosis & 2762 & 56 & 2241 & 51 & 1529 & 58 & 3753 & 33 & 7623 & 57 & 4085 & 41 \\
\hline ADHD & 36 & 0.7 & 33 & 0.7 & 10 & 0.4 & 75 & 0.7 & 77 & 0.6 & 538 & 5 \\
\hline Anxiety & 783 & 16 & 1124 & 26 & 909 & 35 & 1779 & 15 & 2669 & 20 & 1391 & 14 \\
\hline Depression & 1330 & 27 & 1748 & 40 & 1142 & 43 & 2964 & 26 & 4648 & 35 & 2204 & 22 \\
\hline Dementia & 1521 & 31 & 183 & 4 & 157 & 6 & 466 & 4 & 3514 & 26 & 1211 & 12 \\
\hline OCD & 40 & 0.8 & 93 & 2 & 47 & 2 & 216 & 2 & 250 & 2 & 221 & 2 \\
\hline $\mathrm{PD}$ & 136 & 3 & 294 & 7 & 122 & 4 & 525 & 5 & 705 & 5 & 349 & 4 \\
\hline PTSD & 37 & 0.8 & 97 & 2 & 29 & 1 & 197 & 2 & 210 & 2 & 94 & 0.9 \\
\hline Sleep disorders & 761 & 15 & 815 & 19 & 511 & 19 & 1124 & 10 & 1926 & 14 & 1078 & 11 \\
\hline None of the above* & 820 & 17 & 618 & 14 & 321 & 12 & 655 & 6 & 879 & 7 & 1274 & 13 \\
\hline
\end{tabular}

*If a person has an SMI diagnosis, any non-SMI diagnoses will not be included in the numbers below. For those who do not have an SMI diagnosis, all non-SMI diagnoses will be shown (ie, they are not mutually exclusive). 'None of the above' means not having an SMI diagnosis or any of the non-SMI diagnoses in the table.

ADHD, attention deficit hyperactivity disorder; OCD, obsessive compulsive disorder; PD, personality disorder; PTSD, post-traumatic stress disorder; SMI, serious mental illness. 


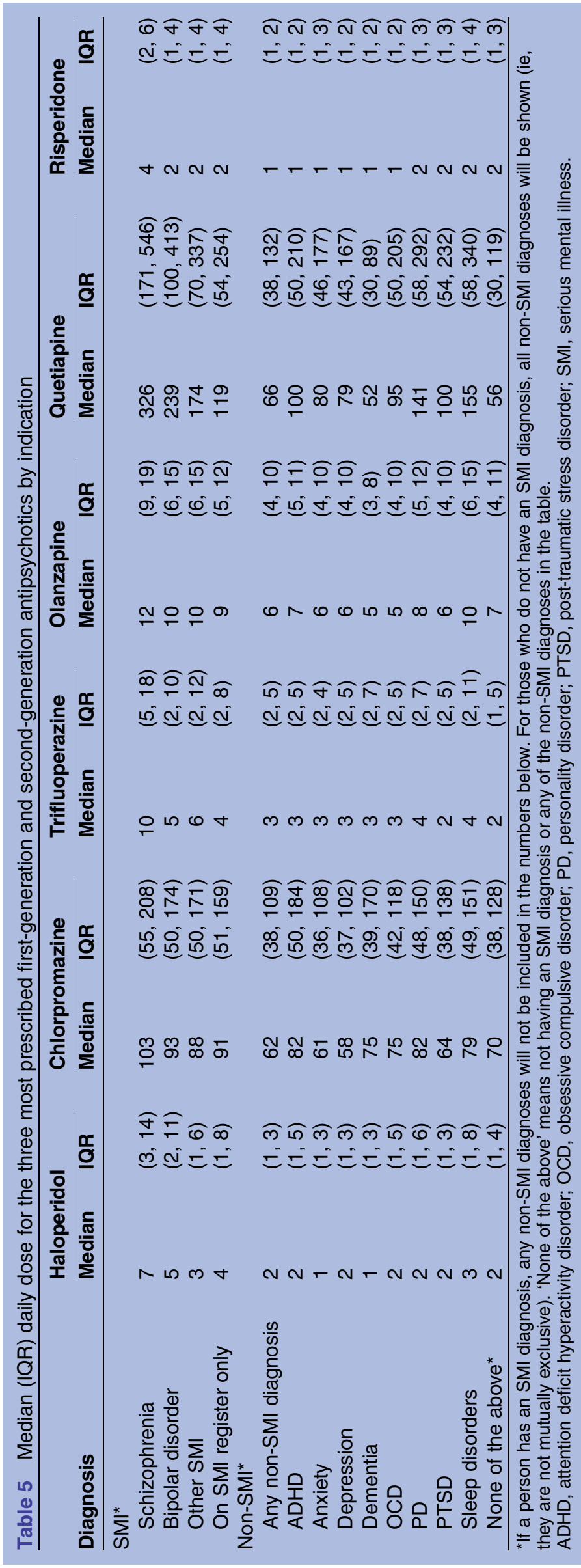

\section{DISCUSSION}

In this study of antipsychotic prescribing in a large primary care database representative of the UK, approximately half of the prescriptions for first-generation and second-generation antipsychotics are issued to people who have no record of SMI, defined as schizophrenia, bipolar affective disorder or other non-organic psychosis in their clinical notes. Furthermore, they are more likely to be prescribed to older people who may be more sensitive to adverse effects such as movement disorders and cardiometabolic risk. When antipsychotics are prescribed to people without SMI, they tend to be given in lower doses and for slightly shorter periods, with the exception of people with ADHD and dementia who receive these drugs for relatively long periods.

Other studies on antipsychotic prescribing relate to an earlier time period prior to the introduction of antipsychotic guidelines in the UK. ${ }^{22}{ }^{23}$ The pattern of prescribing since then has changed over time, ${ }^{24}$ with approximately two-thirds of prescriptions in the current study being for second-generation antipsychotics.

For the first-generation agents, the most common 'non-SMI' mental health diagnoses that we identified were anxiety, depression, sleep disorders and dementia (especially for haloperidol). For the second-generation agents, the same mental health diagnoses were common including dementia, despite the fact that secondgeneration antipsychotics are not recommended in people with dementia due to the risk of stroke and other-cause mortality. ${ }^{1}{ }^{2}$ Reducing the potential harm associated with antipsychotics in dementia has been emphasised as a priority by organisations such as the Department of Health in England and the US Food and Drug Administration. ${ }^{25} 26$ Our findings suggest that further effort is required to decrease primary care antipsychotic prescriptions in dementia and that assessing time trends in antipsychotic prescribing in this group is an important area for future research.

The median daily doses and duration of treatment with antipsychotics tended to be slightly greater in people with SMI diagnoses (especially schizophrenia); however, people with depression, anxiety, personality and sleep disorders still received substantial doses of these agents for relatively long periods of time. For instance, the median daily dose of olanzapine prescribed to people with sleep disorders was $10 \mathrm{mg} /$ day, the same daily dose as prescribed to people with a diagnosis of bipolar disorder and only slightly less than the average dose of $12 \mathrm{mg}$ /day prescribed to people with schizophrenia (table 5). Within the non-SMI group, the median doses of risperidone and quetiapine were also the highest in those with sleep disorders, post-traumatic stress disorder and personality disorder. While the median dose is a crude method of quantifying the amount prescribed for each indication explored in this paper, it does allow us to make comparisons between these diagnoses.

There are a number of possible explanations for the high rates of antipsychotic prescribing to people without 
a psychosis diagnosis. First, it may be that the clinician prescribes antipsychotics because the person does have psychotic symptoms, but the clinician does not assign a label of schizophrenia or other psychosis, either due to patient preference or to avoid the associated stigma with such labels. However, this would suggest that there are large numbers of people with unrecorded psychosis and/or bipolar disorder in primary care. This is not consistent with other researches in UK primary care databases which have shown that rates of schizophrenia and bipolar disorder recorded in the database are similar to those in other epidemiological studies. ${ }^{17}$ Therefore, it seems unlikely that large numbers of people in primary care have psychosis without a corresponding record.

Second, it is possible that in real-life practice, antipsychotics are prescribed quite commonly to people with problems related to depression, anxiety, sleep, dementia and other conditions; despite guidelines recommending caution and only suggesting this as a strategy in the treatment of unresponsive cases. ${ }^{36}$ It may be that clinicians and/or mental health professionals quite frequently add antipsychotics to the treatment plan for people with non-psychotic disorders, either for agitation, poor sleep or anxiety or due to their general reputation as tranquillising medications. Since there were no major differences in the median doses and duration of treatment according to the likely indication, these patterns of prescribing warrant some attention in terms of monitoring side effects particularly weight gain, extra-pyramidal side effects and metabolic impacts such as hyperprolactinaemia, glucose dysregulation and effects on lipid profiles. The current UK policy only recommends physical monitoring for people whom the general practice includes on its SMI register. It may be that this recommendation should be extended to all people prescribed antipsychotics in primary care.

\section{Strengths and limitations}

The primary care databases allow us to study large representative samples of patients in general practice across the UK. THIN has a good record of prescriptions issued and a comparison with dispensing data suggests that the majority of its prescriptions issued are collected, ${ }^{27}$ but of course this may not mean that patients have been actually taking the medication. Primary care diagnoses of SMIs have been validated $;{ }^{16}$ however, this is not the case for some other conditions that had been explored such as ADHD and OCD.

Research with routine clinical data has its limitations; for instance, we could not perform a more detailed assessment of patient characteristics and preferences which may influence treatment decisions. For non-SMI diagnoses such as depression and anxiety, we extracted all diagnoses which had been entered at any time. We did this because GPs do not routinely re-enter diagnoses at each subsequent appointment and we wanted to capture all relevant information regarding the possible indication. A limitation of this method, and of the database, is that we cannot be certain that the decision to prescribe had been temporally related to the mental health condition entered at another time. However, this method does give an indication of the long-term clinical presentation of people without an SMI Read code who have been prescribed antipsychotics. It would be useful to explore the reasons underpinning these high rates of prescribing to groups not traditionally thought eligible for antipsychotic treatment. This might require primary research studies interviewing clinicians and reviewing individual patients. However, further database work could explore symptoms associated with these antipsychotic prescriptions, and the treatment decisions predating the choice of an antipsychotic agent. Also, the same databases could be used to assess how frequently cardiovascular risk factors are measured in this population, especially body mass index, cholesterol and highdensity lipoprotein (HDL) cholesterol, as well as giving some indication of glucose regulation such as HbAlc, random or fasting glucose.

We need to know more about co-prescribing in the people without a diagnosis of psychosis or bipolar disorder, for instance, benzodiazepines and mood stabilisers. We also need to quantify the degree of benefit or harm that may be associated with using such treatments. To what degree do they cause physical and/or mental health problems for the recipients, and to what extent do they lead to symptom remission? A meta-analysis of antipsychotic drugs in major depressive disorder found that although these agents may improve depression symptoms, they have no impact on the functioning or quality of life. ${ }^{28}$ The few existing randomised controlled trials involving people with personality disorders have shown little benefit of antipsychotics over placebo. ${ }^{6} 29$

Finally, it is important to explore whether these agents are discontinued following amelioration of any mental health problem for which they are chosen, and to assess the risks and benefits of stopping such agents in different diagnostic groups.

Contributors DPJO, KW, IP and IN had the original idea for the study. All authors developed the method, analysed and interpreted the results and wrote the manuscript. LM performed the analysis.

Funding This work was funded by the NIHR School for Primary Care Research (grant number 17321).

Disclaimer The funders had no role in study design, data collection and analysis, decision to publish, or preparation of the manuscript.

Competing interests None.

Ethics approval THIN has overall ethical approval from the South East Multicentre Research Ethics Committee (reference number: 07/H1102/103) and further study-specific approval for this study was gained as part of an additional MREC approval from the London Research Ethics Committee. Reference number: 09/H0718/11.

Provenance and peer review Not commissioned; externally peer reviewed. Data sharing statement No additional data are available.

Open Access This is an Open Access article distributed in accordance with the Creative Commons Attribution Non Commercial (CC BY-NC 4.0) license, 
which permits others to distribute, remix, adapt, build upon this work noncommercially, and license their derivative works on different terms, provided the original work is properly cited and the use is non-commercial. See: http:// creativecommons.org/licenses/by-nc/4.0/

\section{REFERENCES}

1. Schneider LS, Dagerman KS, Insel P. Risk of death with atypical antipsychotic drug treatment for dementia: meta-analysis of randomized placebo-controlled trials. JAMA 2005;294:1934-43.

2. Douglas IJ, Smeeth L. Exposure to antipsychotics and risk of stroke: self controlled case series study (electronic article). BMJ 2008;337: a1227.

3. National Institute for Health and Care Excellence. Depression: the treatment and management of depression in adults (update). CG90 2009a. http://guidance.nice.org.uk/CG90 (accessed May 2014).

4. Baldwin DS, Anderson IM, Nutt DJ, et al. Evidence-based guidelines for the pharmacological treatment of anxiety disorders: recommendations from the British Association for Psychopharmacology. J Psychopharmacol 2005;19:567-96.

5. Wilson SJ, Nutt DJ, Alford C, et al. British Association for Psychopharmacology consensus statement on evidence-based treatment of insomnia, parasomnias and circadian rhythm disorders. J Psychopharmacol 2010;24:1577-600.

6. National Institute for Health and Care Excellence. Borderline personality disorder: treatment and management. CG78 2009b. http://www.nice.org.uk/CG78 (accessed May 2014).

7. The Health Improvement Network. London, 2014. http://csdmruk. cegedim.com/ (accessed May 2014).

8. Clinical Practice Research Datalink (CPRD) website. Crown Copyright 2014. http://www.cprd.com/intro.asp (accessed Oct 2014).

9. Lis Y, Mann RD. The VAMP research multi-purpose database in the UK. J Clin Epidemiol 1995;48:431-43.

10. Townsend P, Phillimore P, Beattie A. Health and deprivation: inequality and the North. London: Croom Helm, 1988.

11. Booth N. What are the Read codes? Health Libr Rev 1994;11:177-82.

12. Joint Formulary Committee. British National Formulary (online) London: BMJ Group and Pharmaceutical Press, 2014. http://www. medicinescomplete.com (accessed May 2014).

13. Blak BT, Thompson M, Dattani $\mathrm{H}$, et al. Generalisability of The Health Improvement Network (THIN) database: demographics chronic disease prevalence and mortality rates. Inform Prim Care 2011;19:251-5.

14. Horsfall L, Walters K, Petersen I. Identifying periods of acceptable computer usage in primary care research databases. Pharmacoepidemiol Drug Saf 2013;22:64-9.
15. Maguire A, Blak BT, Thompson M. The importance of defining periods of complete mortality reporting for research using automated data from primary care. Pharmacoepidem Drug Saf 2009;18:76-83.

16. Nazareth I, King M, Haines A, et al. Accuracy of diagnosis of psychosis on general practice computer system. BMJ 1993;307:32-4.

17. Hardoon S, Hayes JF, Blackburn R, et al. Recording of severe mental illness in United Kingdom primary care, 2000-2010. PLoS One 2013;8:e82365.

18. Dave S, Petersen I. Creating medical and drug code lists to identify cases in primary care databases. Pharmacoepidem Drug Saf 2009;18:704-7.

19. Walters K, Rait G, Griffin M, et al. Recent trends in the incidence of anxiety diagnoses and symptoms in primary care. PLOS ONE 2012;7:e4167.

20. Rait G, Walters K, Griffin M, et al. Recent trends in the incidence of recorded depression and depressive symptoms in primary care. $\mathrm{Br} J$ Psychiat 2009;195:520-4.

21. Stata Corporation. Stata statistical software: release 13. College Station, TX: Stata Corporation, 2013.

22. Verdoux H, Tournier M, Bégaud B. Antipsychotic prescribing trends: a review of pharmaco-epidemiological studies. Acta Psychiatr Scand 2010;121:4-10.

23. Kaye JA, Bradbury BD, Jick $\mathrm{H}$. Changes in antipsychotic drug prescribing by general practitioners in the United Kingdom from 1991 to 2000: a population-based observational study. Br J Clin Pharmacol 2003;56:569-75.

24. Prah P, Petersen I, Nazareth I, et al. National changes in oral antipsychotic treatment for people with schizophrenia in primary care between 1998 and 2007 in the United Kingdom. Pharmacoepidem Drug Saf 2012;21:161-9.

25. Department of Health. The use of antipsychotic medication for people with dementia: time for action. London: Department of Health, 2009.

26. U.S. Food and Drug Adminstration. Public Health Advisory: deaths with antipsychotics in elderly patients with behavioral disturbances, 2005. http://www.fda.gov/Drugs/DrugSafety/PostmarketDrugSafety InformationforPatientsandProviders/DrugSafetylnformationfor HeathcareProfessionals/PublicHealthAdvisories/ucm053171.htm (accessed May 2014).

27. The NHS Information Centre PaPCS. Prescribing compliance: a review of the proportion of prescriptions dispensed. 2011. http:// www.hscic.gov.uk/pubs/presccompliance (accessed May 2014).

28. Spielmans Gl, Berman MI, Linardatos E, et al. Adjunctive atypical antipsychotic treatment for major depressive disorder: a meta-analysis of depression, quality of life, and safety outcomes. PLoS Med 2013;10: e1001403.

29. Ingenhoven T, Lafay $\mathrm{P}$, Rinne $\mathrm{T}$, et al. Effectiveness of pharmacotherapy for severe personality disorders: metaanalyses of randomized controlled trials. J Clin Psychiatry 2010;71:14-25. 